\title{
TUBEROUS SCLEROSIS COMPLEX: CLINICAL SPECTRUM AND EPILEPSY: A RETROSPECTIVE CHART REVIEW STUDY
} sclerosis complex (TSC) is an autosomal dominant genetic neurocutaneous disorder, with heterogeneous manifestations. We aimed to review the clinical presentation of TSC and its association with epilepsy among Saudi population. This was a retrospective chart review study of 88 patients diagnosed with TSC with or without epilepsy. In 38.6\% of patients, symptoms began before 1 year of age. The most frequent initial manifestations of TSC were new onset of seizures (68.2\%), skin manifestations (46.6\%) and development delay (23.9\%). During the evolution of the disease $65.9 \%$ had epilepsy, 17\% facial angiofibromas, $13.6 \%$ Shagreen patch, $18.2 \%$ heart rhabdomyomas and $12.5 \%$ retinal hamartomas. The genetic study for TSC diagnosis was done for 44 patients, $42(95,4 \%)$ of them were genetically confirmed, for whom 13 patients had TSC1 mutation (29.5\%), 29 patients were carrying TSC2 gene mutation (65.9\%), Genetic test for TSC 1 and TSC 2 were negative for 2 patients (4.5\%) despite positive gene mutation in their relative with TSC. The most common manifestations were central nervous system (predominantly epilepsy) and dermatological manifestations. Most of the patients develop epilepsy with multiple seizure types. TSC 2 mutation is more common than TSC 1 mutation.

Keywords Tuberous Sclerosis Complex • manifestations • epilepsy • TSC1 • TSC2

\section{INTRODUCTION}

Tuberous sclerosis complex (TSC) is an autosomal dominant genetic multisystem disorder which mainly results from the lack of functional Tsc1-Tsc2 complex due to mutations in TSC1 or TSC2 genes encoding hamartin and tuberin respectively, and belongs to a group of neurocutaneous syndromes together with Sturge- Weber syndrome, von HippelLindau disease, and neurofibromatosis [1,2]. Pathologically, TSC is defined as a disorder of cell migration, proliferation and differentiation.

[3] The incidence rates of TSC were estimated to be $1 / 6,000$ and $1 / 10,000[1,4,5]$ among live births; however previous studies [2,6] reported that there are undetected mild TSC cases and this makes the true incidence likely to be higher. Mutations in TSC1or TSC2 genes were found in approximately $85 \%$ of patients with TSC $[7,8]$. The role of TSC1-TSC2 protein complex is an upstream regulator of mammalian target of rapamycin (mTOR), any disruption of this function results in over activation of $\mathrm{mTOR}$ and dysregulated growth control, hence explaining the fundamental pathological mechanism of TSC disorder [1,9].

The clinical diagnosis of TSC is challenging as the disease is highly variable in clinical presentation, findings, and its manifestations continue to develop over the lifetime of the affected individuals and can vary widely between even closely related individuals [10]. In the recommendations of the 2012 international TSC consensus conference for TSC diagnostic criteria update [10], the new inclusion of genetic testing results was one of the key changes compared with 1998 criteria, keeping on the point that Clinical features of TSC continue to be a principal means of diagnosis with the presence of two major features or one major plus two minor features for a definitive diagnosis.

TSC is characterized by the development of hamartias (non-growing lesions) and hamartomas which represent the primary manifestations of the disease and affect various organ systems involving the central
Sulaiman Almobarak ${ }^{1 *}$,

Mohammad Almuhaizea ${ }^{2}$

Musaad Abukhaled ${ }^{2}$,

Suad Alyamani ${ }^{2}$,

Omar Dabbagh ${ }^{2}$

Aziza Chedrawi ${ }^{2}$,

Sameena Khan ${ }^{2}$,

Hesham Aldhalaan ${ }^{2}$

King Faisal Specialist Hospital \& Research Center Riyadh, Saudi Arabia

2 Department of Neuroscience, King Faisal Specialist Hospital \& Research Center, Riyadh Saudi Arabia

Received 04 July 2018

accepted 14 October 2018

*E-mail:dr.sulaiman.b.m@hotmail.com

(cc) BY-NC-ND $\odot 2018$ Sulaiman Almobarak et al., published by De Gruyter.

This work is licensed under the Creative Commons Attribution-NonCommercial-NoDerivs 4.0 License.

nervous system (CNS), dermatological (facial angiofibromas), kidneys (renal angiomyolipoma), Circulatory (cardiac rhabdomyoma), eyes (retinal hamartomas) and respiratory $[1,10,11]$. Usually, the first detected manifestations are infantile spasms, neurodevelopmental and skin manifestations also typically present early in life, on the other hand, renal manifestations are often observed in adolescence or adulthood and respiratory manifestations are typically present in adult and almost exclusively symptomatic in female TSC patients $[2,10]$.

The CNS is the most commonly and severely affected systems in TSC patients, where brain MRI imaging frequently shows structural abnormalities including cortical tubers and subependymal nodules (SENs), which can transform into subependymal giant cell astrocytomas (SEGA), and consequently, patients with TSC often suffer from debilitating neurological defects including epilepsy, mental retardation, and autism spectrum disorder (ASD) [12]. In recent times, these 
structural abnormalities and pathological changes were thought to be responsible for TSC patients neurological phenotype; however, current studies have proposed that subtler microscopic changes like aberrant white matter connectivity, which cannot be envisioned with regular MR imaging techniques, play a role in causing epilepsy, ASD, behavioral problems and cognitive deficits [13]. Previous studies reported that epilepsy is the most common and troublesome symptom in TSC patients, seen in $80-90 \%$ of the affected individuals, often refractory to treatment and a significant source of morbidity and mortality [14].

Epilepsy begins in the first year of life in majority of the patients with TSC and is very difficult to handle, and poor control together with early onset of seizures are considered as traditional risk factors for poor neuropsychological outcome among those patients $[2,15,16]$. Epilepsy usually begins in the first three years of life although onset at any age is a possibility. Drug resistant epilepsy is found most commonly in TSC patients. Seizures are classified by ILAE into 3 major categories; focal onset, generalized onset and seizure of unknown onset. Generalized seizures occupy a large portion of brain, it originates at some point and rapidly engages bilaterally distributed networks but not necessarily the entire cortex. Focal seizures on the other hand limits to one hemisphere. Generalized seizure might be of motor onset like tonic- clonic or other motor onset, or it can be of nonmotor onset like absence. Focal are optionally classified as aware or impaired awareness. Impaired awareness and loss of consciousness are not the same. If the awareness is impaired at any time during a seizure, impaired awareness should be included. After the level of awareness, focal is classified as of motor onset or nonmotor onset. The expanded classification includes subdivision focal to bilateral tonic clonic. For generalized seizures level of awareness is omitted as awareness is mostly impaired in most generalized seizures. Unknown onset refers to seizures in which the onset is unknown but other manifestations are known, it is also classified as having motor (tonic clonic or other motor) or nonmotor onset. It is further clarified as unclassified for the events that are clearly seizures yet unclassifiable [17]. The prevalence of ASD and intellectual disability among TSC patients was reported to be $17-50 \%$ and $60 \%$, respectively $[1,2,18,19]$. Additional neuropsychiatric problems including aggressive/disruptive behavior, attentiondeficit/hyperactivity disorder (ADHD), anxiety and depression have been reported in some TSC patients [12].

Data about TSC and its clinical manifestations are scarce in Saudi Arabia and even the whole Gulf Cooperation Council (GCC) countries. The lack of such data that gather information across the broad spectrum of manifestations, analyze the combinations of the involved organ systems and document the age of onset, description of seizure and its management and progression of clinical features will compound barriers to improve the quality and coordination of care in TSC. In the current study, we used patients' charts to study the natural history of TSC in a cohort of patients in Saudi Arabia. The aim of this study was to review the clinical presentation of TSC, its association with epilepsy and the natural history of epilepsy in this genetic disease among Saudi population.

\section{METHODS}

We included all patients (88) with a confirmed diagnosis of TSC (based on 2012 International Tuberous Sclerosis Complex Consensus Conference) with or without epilepsy in the period between 1999-2016. Predesigned questionnaire included questions that covered the patients' demographic information, clinical and neurological manifestations, seizures description, antiepileptic drugs, systemic examinations (CNS, skin, heart, kidney, and eyes), genetic study, neurophysiology (electroencephalography (EEG)) and imaging (MRI, CT, USG abdomen and others) was used to collect the data.

We performed a retrospective chart review study. Charts of the 88 patients were reviewed for the above mentioned items, and the genetic, clinical and neurological manifestations and outcomes were described based on patients' last visit. Genetic testing of the TSC1 and TSC2 genes was performed.

Statistical analysis
Data were analyzed by using Statistical Package for Social Studies (SPSS version 22). Chi-square test and Fisher's exact test were used for categorical variables. A p-value $<0.05$ was considered statistically significant.

Ethical Approval

The study was approved by the research ethics committee at King Faisal Specialized Hospital \& Research Center (KFSH\&RC) (ORA\#2151057)

\section{RESULTS:}

A total of 88 patients with confirmed TSC diagnosis were included in the current study. The cohort had a mean age of $16.56 \pm 14.21$, the highest percentage of them (23.9\%) were in the age group of 11-14 years old followed by $22.7 \%$ aged 7-10 years old. (Table 1).

The highest percentage (38.6\%) of the participants had age of onset less than one year for the first time of symptoms presentation, followed by $30.7 \%, 15.9 \%$, and $14.8 \%$ at the age of $1-5,6-10$, and $>10$ years, respectively. (Fig. 1)

Seizure was the highest prevalent symptom of TSC among the studied cohort accounting at $68.2 \%$ followed by skin manifestations at $46.6 \%$ and development delay at $23.9 \%$ (Table 2).

Seizures and skin manifestations were highly prevalent in males compared to females $(69.6 \%$ and $48.2 \%$ versus $65.65 \%$ and $43.8 \%$, respectively). On the other hand, the prevalence of global development delay was higher in females compared to males ( $25 \%$ and $23.2 \%$, respectively). The prevalence of other manifestations including delayed learning, ADHD, and autism, were as following: $11.4 \%$, $11.4 \%, 6.8 \%$, and $9.1 \%$ respectively (Table 3 ).

The patients were categorized according to their age groups into two groups: $<14$ (children) and $\geq 14$ years old (adults). It was observed that the prevalence of skin manifestations, development delay, ADAH and autism was higher in children compared to adults (48\%, $29 \%, 12 \%$ and $10 \%$ versus $24 \%, 17 \%, 0 \%$ and $8 \%$, respectively) (Table 4 ).

When symptoms were compared by the time of its first presentation, the highest prevalence of each of the assessed symptoms was as following: seizures $(78.6 \%)$ at the age of onset 
Table 1: Demographic characteristic

\begin{tabular}{lcc}
\hline & N & $\%$ \\
\hline Age $($ mean \pm SD) & $16.56 \pm 14.21$ & 12.5 \\
$<6$ y & 11 & 22.7 \\
$7-10 y$ & 20 & 23.9 \\
$11-14 y$ & 21 & 11.4 \\
$15-18 y$ & 10 & 14.8 \\
$19-25 y$ & 13 & 14.8 \\
$>25 y$ & 13 & \\
Gender & & 63.6 \\
Male & 56 & 36.4 \\
Female & 32 & \\
Birth place (Region) & & 46.6 \\
Central & 41 & 11.4 \\
Eastern & 10 & 9.1 \\
Western & 8 & 12.5 \\
Southern & 11 & 19.3 \\
Northern & 17 & 1.1 \\
Other & 1 & \\
\hline
\end{tabular}

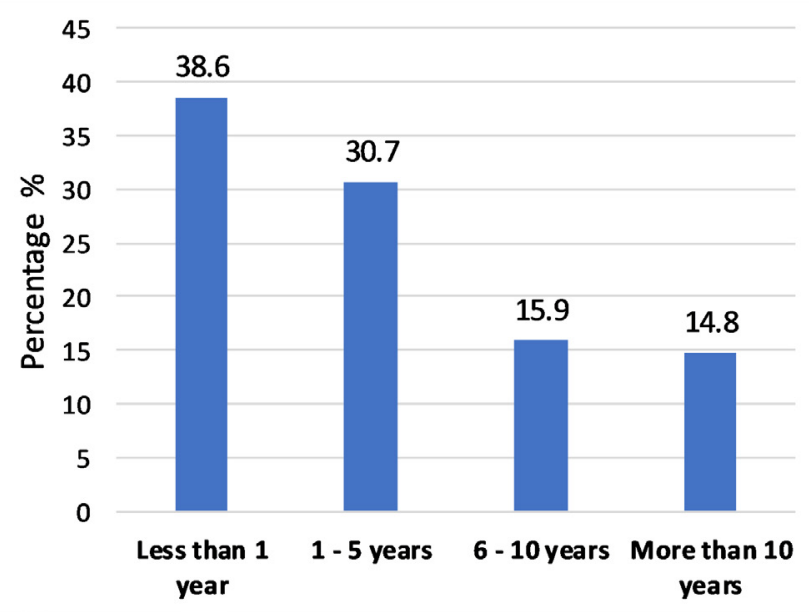

Fig. 1: Time of first presentation of symptoms

Table 2: Clinical manifestations of TSC among the studied cohort

\begin{tabular}{ccc}
\hline Symptoms & N & $\%$ \\
\hline Seizures & 60 & 68.2 \\
Skin Manifestations & 41 & 46.6 \\
Developmental Delay & 21 & 23.9 \\
Delayed Learner (MR) & 10 & 11.4 \\
Delayed Language & 10 & 11.4 \\
ADHD & 6 & 6.8 \\
Autism & 8 & 9.1 \\
Other & 6 & 6.8 \\
\hline
\end{tabular}

from 6-10 years, skin manifestations (64.7\%) at less than one year $(P<0.01)$, development delay $(32.4 \%)$ at less than one year $(P<0.31)$, delayed learning and delayed language $(23.1 \%$ for each) at time from $>10$ years $(P<0.48$ and $<0.20$, respectively), and ADAH autism and others ( $14.3 \%$ for each) at age of onset of $6-10$ years (Table5).

The genetic study for TSC diagnosis was done for 44 patients, 42 (95.4\%) of them were genetically confirmed, for whom 13 patients had TSC1 mutation (29.5\%), 7 of them were females (53.8\%). 29 patients were carrying TSC2 gene mutation (65.9\%), 20 of them were male (68.9\%). Two (4.5\%) patients had their genetic test for TSC1 and TSC2 negative despite positive gene mutation in their relative with TSC. Three patients who were genetically confirmed with TSC2 also had a mutation in PKD1/PKD2 gene of autosomal dominant polycystic kidney disease which indicates more severe form of the disease (Table 6).

Half of the patients had sphincter control during the seizures. Seizures age of onset was less than one year in $61.0 \%$ of the patients. For the number and type of antiepileptic drugs used in our cohort, Carbamazepine (Tegretol) was the most commonly used (42.3\%), followed by Levetiracetam (Keppra) (39.4\%), Valproic acid (Depakine|) (36.6\%), and Vigabatrin (Sabril) (31.0\%). The seizure was controlled only in $54.5 \%$ of the patients. The seizures observed were 49 generalized seizures, 16 focal seizures, 14 were only spasms and 4 were unable to describe the type of seizure.

Systemic examinations of the studied cohort were reviewed for skin examinations, Cardiac Rhabdomyoma, prevalence of kidney complications, eye examinations, prevalence of seizures and Global Development Delay (GDD) (Table 7).

The results of psychological evaluation showed that, among the studied TSC cohort, the prevalence of ADHD and autism was $26.1 \%$ and $17 \%$, respectively, being higher in patients aged $<14$ at $28.85 \%$ and $19.23 \%$ compared to those aged $\geq 14$ at $22.22 \%$ and $13.89 \%$ respectively, but the difference was nonsignificant in both cases $(P<0.23$ and $<0.25$, 
Translational Neuroscience

respectively).

\section{DISCUSSION}

To the best of our knowledge, the current study represents the first study reporting the clinical spectrum and epilepsy among TSC patients in Saudi Arabia and the whole Gulf Cooperation Council (GCC) countries. It might contribute towards a better understanding of the disease complexity and its management in the community setting. We reported comprehensive data on known TSC manifestations, including their prevalence, age of onset and their differences by age, gender and the time of their presentations.

In contrast to what had been previously reported in the literature $[7,8]$, the current study has a higher percentage of patients with genetically confirmed TSC genes (TSC1 and TSC2) mutations ( $85 \%$ versus 95,4\%). TSC2 mutation was higher than TSC1, a finding which is in line with Dabora SL et al study [20].

The prevalence of seizure as one of the initial TSC manifestations was lower compared to what had been recently reported from a study published in 2017 by Rubilar C. et al [21] at $68.2 \%$ and $73.85 \%$ respectively, while the same study reported a lower prevalence of delayed development $(4.8 \%)$ compared to the current one (23.9\%).

Against what we expected based on previous research studies, a lower prevalence of some manifestations was recorded. These manifestations include seizures, autism and delayed learner, where previous studies reported a prevalence of $80-90 \%, 17-50 \%$ and $60 \%$, compared to $65.9 \%, 17.0 \%$ and $11.4 \%$, respectively in the current study $[1,2,14,18,19]$. Similarly, the prevalence of cardiac rhabdomyomas, facial angiofibroma, shagreen batches, ungula fibroma, and retinal hamartomas at $18.2 \%, 17.0 \%, 13.6 \%, 1.1 \%$, and $12.5 \%$, respectively, was lower compared to a similar study in which the prevalence of these manifestations was $47.6 \%, 47.6 \%, 23.8 \%, 12.0 \%$ and $35.7 \%$, respectively [21]. Such difference is probably likely to represent under-diagnosis and/or under reporting of the manifestations, highlighting inadequate care and improper data recording. Northrup $\mathrm{H}$ et al. reported
Table 3: Symptoms of TSC by gender

\begin{tabular}{ccccccc}
\hline & \multicolumn{2}{c}{ Male } & \multicolumn{2}{c}{ Female } & P value \\
\cline { 1 - 4 } Symptoms & N & $\%$ & N & $\%$ & 0.697 \\
Seizures & 39 & 69.6 & 21 & 65.6 & 0.686 \\
Skin Manifestations & 27 & 48.2 & 14 & 43.8 & 0.85 \\
Developmental Delay & 13 & 23.2 & 8 & 25.0 & 9.4 & 0.657 \\
Delayed Learner (MR) & 7 & 12.5 & 3 & 12.5 & 0.8 \\
Delayed Language & 6 & 10.7 & 4 & 6.3 & 0.873 \\
Behavioral Problems-ADHD & 4 & 7.1 & 2 & 6.3 & 0.483 \\
Behavioral Problems-Autism & 6 & 10.7 & 2 & 15.6 & 0.013 \\
\hline
\end{tabular}

Table 4: Symptoms of TSC by age group

\begin{tabular}{cccccc} 
& \multicolumn{2}{c}{ age $\leq 14$} & \multicolumn{2}{c}{ age $>14$} & \multirow{2}{*}{ P value } \\
\cline { 1 - 4 } & N & $\%$ & N & \% & \\
Seizures & 34 & 65 & 26 & 72 & 0.498 \\
Skin Manifestations & 25 & 48 & 16 & 44 & 0.737 \\
Developmental Delay & 15 & 29 & 6 & 17 & 0.188 \\
Delayed Learner (MR) & 2 & 4 & 8 & 22 & 0.008 \\
Delayed Language & 5 & 10 & 5 & 14 & 0.535 \\
Behavioral Problems-ADHD & 6 & 12 & 0 & 0 & 0.035 \\
Behavioral Problems-Autism & 5 & 10 & 3 & 8 & 0.837 \\
Other & 3 & 6 & 3 & 8 & 0.639 \\
\hline
\end{tabular}

Table 5: Symptoms by the time of the first presentation

\begin{tabular}{|c|c|c|c|c|c|c|c|c|c|}
\hline & \multicolumn{2}{|c|}{$\begin{array}{l}\text { Less than } \\
\text { one year }\end{array}$} & \multicolumn{2}{|c|}{$\begin{array}{c}\text { From } 1 \text { to } 5 \\
\text { Years }\end{array}$} & \multicolumn{2}{|c|}{$\begin{array}{c}\text { From } 6 \text { to } \\
10 \text { years }\end{array}$} & \multicolumn{2}{|c|}{$\begin{array}{c}\text { More than } \\
10 \text { years }\end{array}$} & \multirow[t]{2}{*}{$P$ value } \\
\hline & $\mathbf{N}$ & $\%$ & $\mathbf{N}$ & $\%$ & $\mathbf{N}$ & $\%$ & $\mathbf{N}$ & $\%$ & \\
\hline Seizures & 26 & 76.5 & 18 & 66.7 & 11 & 78.6 & 5 & 38.5 & 0.069 \\
\hline Skin Manifestations & 22 & 64.7 & 12 & 44.4 & 6 & 42.9 & 1 & 7.7 & 0.006 \\
\hline Developmental Delay & 11 & 32.4 & 6 & 22.2 & 1 & 7.1 & 3 & 23.1 & 0.315 \\
\hline Delayed Learner (MR) & 4 & 11.8 & 2 & 7.4 & 1 & 7.1 & 3 & 23.1 & 0.486 \\
\hline Delayed Language & 2 & 5.9 & 2 & 7.4 & 3 & 21.4 & 3 & 23.1 & 0.202 \\
\hline Behavioral Problems-ADHD & 2 & 5.9 & 2 & 7.4 & 2 & 14.3 & 0 & 0.0 & 0.524 \\
\hline Behavioral Problems-Autism & 2 & 5.9 & 3 & 11.1 & 2 & 14.3 & 1 & 7.7 & 0.79 \\
\hline Other & 2 & 5.9 & 1 & 3.7 & 2 & 14.3 & 1 & 7.7 & 0.636 \\
\hline
\end{tabular}


Table 6: Seizure description

\begin{tabular}{|c|c|c|}
\hline & $\mathrm{N}$ & $\%$ \\
\hline \multicolumn{3}{|l|}{ Body } \\
\hline Whole Body & 42 & 47.7 \\
\hline Right Sided & 6 & 6.8 \\
\hline Left Sided & 16 & 18.2 \\
\hline One Leg & 1 & 1.1 \\
\hline One Arm & 8 & 9.1 \\
\hline Cannot Describe & 6 & 6.8 \\
\hline \multicolumn{3}{|l|}{ Movement } \\
\hline Clonic Jerks & 2 & 2.3 \\
\hline Stiffness (Tonic) & 14 & 15.9 \\
\hline Tonic and Clonic (Jerking and Stiffness) & 33 & 37.5 \\
\hline Myoclonic Jerks & 16 & 18.2 \\
\hline Infantile Spasm & 14 & 15.9 \\
\hline Cannot Describe & 4 & 4.5 \\
\hline Atonic & 0 & 0.0 \\
\hline Gelastic Seizures & 0 & 0.0 \\
\hline \multicolumn{3}{|l|}{ Eyes } \\
\hline Upward Gaze & 19 & 21.6 \\
\hline Closed Eyes & 0 & 0.0 \\
\hline Right Deviation & 1 & 1.1 \\
\hline Left Deviation & 6 & 6.8 \\
\hline Stare & 9 & 10.2 \\
\hline Blink and Stare & 8 & 9.1 \\
\hline No Change & 4 & 4.5 \\
\hline Cannot Tell & 15 & 17.0 \\
\hline Twitching & 0 & 0.0 \\
\hline \multicolumn{3}{|l|}{ Skin Color } \\
\hline Blue & 11 & 12.5 \\
\hline Pale & 4 & 4.5 \\
\hline No Change & 32 & 36.4 \\
\hline Cannot Describe & 16 & 18.2 \\
\hline Missing & 25 & 28.4 \\
\hline Sphincter Control & 44 & 50.0 \\
\hline \multicolumn{3}{|l|}{ Mouth } \\
\hline Dry & 4 & 4.5 \\
\hline Drooling & 5 & 5.7 \\
\hline Foam & 2 & 2.3 \\
\hline Tongue Bite & 1 & 1.1 \\
\hline Cannot Describe & 1 & 1.1 \\
\hline \multicolumn{3}{|l|}{ How Often? } \\
\hline Daily & 35 & 39.8 \\
\hline Weekly & 9 & 10.2 \\
\hline Monthly & 3 & 3.4 \\
\hline Other & 13 & 14.8 \\
\hline \multicolumn{3}{|l|}{ Condition After Seizure } \\
\hline Asleep & 13 & 14.8 \\
\hline Drowsy & 8 & 9.1 \\
\hline Alert & 12 & 13.6 \\
\hline Confused & 8 & 9.1 \\
\hline
\end{tabular}

that cardiac rhabdomyomas are the main characteristic of TSC which require cardiological follow-up with echocardiography [10].

On the other hand, the prevalence of Angiomyofibroma reported in the current study was higher compared to that reported by Rubilar C. et al at $26.1 \%$ and $16.7 \%$, respectively, while a slightly higher prevalence of renal cyst was reported compared to the same study (14.8\% and $14.3 \%$ ) [21].

In majority of the patients the initial manifestations were detected before the first year of life, which is in line with what is reported in the literature [22]. In most patients the onset of seizure was earlier than 1 year of age which are rarely observed in patients without this disease [10], therefore, the lower prevalence reported in our study emphasize the importance of addition to early onset, epilepsy was difficult to manage, requiring administration of two or three antiepileptic drugs with poor outcomes, a finding similar to the reported in previous studies $[2,15,16]$. Only $15.9 \%$ of the patients with epilepsy evolved with infantile spasms, which is lower than reported in the literature, which describes a frequency of infantile spasms of $48.7 \%$ [21]. Vigabatrin is the first line treatment of focal seizures in infant TSC patients. Then other Antiepileptic drugs (AEDs) are given such as ACTH which is effective for infantile spasms in TSC patients. If first line treatment has failed, AED combination therapy should be initiated. If two consecutive AEDs fail, presurgical evaluation is recommended. Surgery marks the highest probability to abolish seizures. In nonsurgical patients or patients who fail surgeries, ketogenic diet is suggested. After ketogenic diet, vagus nerve stimulation is the option [23].

In accordance with the literature [20], our results showed that ungual fibromas are less common compared to some other TSC skin findings, with a higher frequency in older patients, and its later onset, typically in the second decade or later [24], is the cause of the greater frequency in adults. Thus, their usefulness in diagnosis is usually limited to adolescents and adults. The current study result in regards to a significant higher prevalence of facial angiofibroma in adults is in contrast to 
what had been previously reported that its onset among TSC patients typically ranges between ages 2 and 5 years [25].

Renal manifestations are considered an important source of morbidity and mortality in TSC. In a published study that assessed mortality associated with TSC [26], renal problems were the second leading cause of premature death after severe intellectual disability. The two renal pathologies most commonly seen in TSC are angiomyolipomas and cysts, the first are more prevalent, and the frequency of renal lesions were positively correlated with age [27]. These findings are in agreement with the current study.

Limitations: The limitations for the current study are typical for retrospective studies, where data are limited by the level of detail and quality of information recorded. The prevalence of some manifestations is likely to be under reported.

\section{CONCLUSION}

The study shows the nature of TSC among Saudi population, with patients presenting with a broad spectrum of manifestations, the prevalence of which was estimated and the most common manifestations were central nervous system (predominantly epilepsy) and dermatological manifestations, the estimated prevalence was mostly lower compared to the literature. Most patients develop epilepsy with multiple seizure types and they did not achieve seizure freedom however; most of them were controlled on 2-3 antiepileptic medications.
Table 7: Complications of TSC by age groups

\begin{tabular}{|c|c|c|c|c|c|c|c|}
\hline \multirow[b]{2}{*}{ Skin } & \multicolumn{2}{|c|}{ All } & \multicolumn{2}{|c|}{ Age $<14$ y } & \multicolumn{2}{|c|}{ Age $\geq 14 y$} & \multirow{2}{*}{$\begin{array}{c}P \\
\text { value }\end{array}$} \\
\hline & $\mathrm{N}$ & $\%$ & $\mathrm{~N}$ & $\%$ & $\mathrm{~N}$ & $\%$ & \\
\hline $\begin{array}{l}\text { Hypopigmented Macules (Ash Leaf } \\
\text { Spots) }\end{array}$ & 47 & 53.4 & 28 & 53.85 & 19 & 52.78 & 0.921 \\
\hline Shagreen Patch & 12 & 13.6 & 4 & 7.69 & 8 & 22.22 & 0.063 \\
\hline $\begin{array}{l}\text { Facial Angiofibroma/Adenoma } \\
\text { Sebaceum }\end{array}$ & 15 & 17.0 & 5 & 9.62 & 10 & 27.78 & 0.026 \\
\hline Gingival Fibroma & 0 & 0.0 & 0 & 0.00 & 0 & 0.00 & \\
\hline Periungual Fibroma & 1 & 1.1 & 0 & 0.00 & 1 & 2.78 & 0.409 \\
\hline Other & 6 & 6.8 & 1 & 1.92 & 5 & 13.89 & 0.040 \\
\hline Cardiac Rhabdomyoma & 16 & 18.2 & 13 & 25.00 & 3 & 8.33 & 0.023 \\
\hline \multicolumn{8}{|l|}{ Kidney } \\
\hline Polycystic Kidney & 4 & 4.5 & 2 & 3.85 & 2 & 5.56 & 0.491 \\
\hline Renal Cyst & 13 & 14.8 & 6 & 11.54 & 7 & 19.44 & 0.804 \\
\hline Angiomyofibroma & 23 & 26.1 & 9 & 17.31 & 14 & 38.89 & 0.136 \\
\hline \multicolumn{8}{|l|}{ Eye } \\
\hline Retinal Hamartoma & 11 & 12.5 & 7 & 13.46 & 4 & 11.11 & 0.526 \\
\hline CNS(Seizures) & 58 & 65.9 & 36 & 69.23 & 22 & 61.11 & 0.002 \\
\hline GDD & 34 & 38.6 & 24 & 46.15 & 10 & 27.78 & 0.003 \\
\hline Movement Disorder & 7 & 8.0 & 3 & 5.77 & 4 & 11.11 & 0.557 \\
\hline \multicolumn{8}{|l|}{ Psychological Evaluation } \\
\hline ADHD & 23 & 26.1 & 15 & 28.85 & 8 & 22.22 & 0.231 \\
\hline Autism & 15 & 17.0 & 10 & 19.23 & 5 & 13.89 & 0.252 \\
\hline
\end{tabular}

TSC 2 mutation is more common than TSC 1 DISCLOSURE mutation. TSC 2 mutation is more common in male. On the other hand, TSC 1mutation is almost equal in both genders with slight female predominance. A very little number of patients $(4.5 \%)$ can have negative gene test in presence of clinical manifestation of TSC.

\section{References}

[1] Curatolo P, Bombardieri R, Jozwiak S. Tuberous sclerosis. Lancet. 2008;372:657-68. doi:10.1016/S0140-6736(08)61279-9.

[2] Crino PB, Nathanson KL, Henske EP. The tuberous sclerosis complex. N Engl J Med. 2006;355:1345-56. doi:10.1056/NEJMra055323.

[3] Curatolo P, Verdecchia M, Bombardieri R. Tuberous sclerosis complex: a review of neurological aspects. Eur J Paediatr Neurol. 2002;6:15-23. doi:10.1053/ejpn.2001.0538.

[4] Osborne JP, Fryer A, Webb D. Epidemiology of tuberous sclerosis. Ann NY Acad Sci. 1991;615:125-7.

[5] O'Callaghan FJ, Shiell AW, Osborne JP, Martyn CN. Prevalence of tuberous sclerosis estimated by capture-recapture analysis. Lancet. 1998;351:1490. doi:10.1016/S0140-6736(05)78872-3.
[6] Webb DW, Osborne JP. Tuberous sclerosis. Arch Dis Child. 1995;72:471-4.

[7] European Chromosome 16 Tuberous Sclerosis Consortium. Identification and characterization of the tuberous sclerosis gene on chromosome 16. Cell. 1993;75:1305-15.

[8] van Slegtenhorst $M$, de Hoogt $R$, Hermans $C$, Nellist $M$, Janssen $B$, Verhoef $S$, et al. Identification of the tuberous sclerosis gene TSC1 on chromosome 9q34. Science. 1997;277:805-8.

[9] Kwiatkowski DJ, Manning BD. Tuberous sclerosis: a GAP at the crossroads of multiple signaling pathways. Hum Mol Genet. 2005;14 Spec No. 2:R251-258. doi:10.1093/hmg/ddi260.

[10] Northrup H, Krueger DA, International Tuberous Sclerosis Complex 
Consensus Group. Tuberous sclerosis complex diagnostic criteria update: recommendations of the 2012 linternational Tuberous Sclerosis Complex Consensus Conference. Pediatr Neurol. 2013;49:243-54. doi:10.1016/j.pediatrneurol.2013.08.001.

[11] Rosser T, Panigrahy A, McClintock W. The diverse clinical manifestations of tuberous sclerosis complex: a review. Semin Pediatr Neurol. 2006;13:27-36. doi:10.1016/j.spen.2006.01.008.

[12] Muzykewicz DA, Newberry P, Danforth N, Halpern EF, Thiele EA. Psychiatric comorbid conditions in a clinic population of 241 patients with tuberous sclerosis complex. Epilepsy Behav. 2007;11:506-13. doi:10.1016/j.yebeh.2007.07.010.

[13] Jülich K, Sahin M. Mechanism-based treatment in tuberous sclerosis complex. Pediatr Neurol. 2014;50:290-6. doi:10.1016/j. pediatrneurol.2013.12.002.

[14] Holmes GL, Stafstrom CE, Tuberous Sclerosis Study Group. Tuberous sclerosis complex and epilepsy: recent developments and future challenges. Epilepsia. 2007;48:617-30. doi:10.1111/j.15281167.2007.01035.x.

[15] Cusmai R, Moavero R, Bombardieri R, Vigevano F, Curatolo P. Longterm neurological outcome in children with early-onset epilepsy associated with tuberous sclerosis. Epilepsy Behav. 2011;22:735-9. doi:10.1016/j.yebeh.2011.08.037.

[16] Humphrey A, Neville BGR, Clarke A, Bolton PF. Autistic regression associated with seizure onset in an infant with tuberous sclerosis. Dev Med Child Neurol. 2006;48:609-11. doi:10.1017/ S0012162206001277.

[17] Savini MN, Mingarelli A, Vignoli A, La Briola F, Chiesa V, Peron A, et al. Ictal signs in tuberous sclerosis complex: Clinical and video-EEG features in a large series of recorded seizures. Epilepsy Behav EB. 2018;85:14-20. doi:10.1016/j.yebeh.2018.05.027.

[18] Curatolo P, Moavero R, Roberto D, Graziola F. Genotype/Phenotype Correlations in Tuberous Sclerosis Complex. Semin Pediatr Neurol. 2015;22:259-73. doi:10.1016/j.spen.2015.10.002.
[19] Kothare SV, Singh K, Hochman T, Chalifoux JR, Staley BA, Weiner HL, et al. Genotype/phenotype in tuberous sclerosis complex: associations with clinical and radiologic manifestations. Epilepsia. 2014;55:10204. doi:10.1111/epi.12627.

[20] Dabora SL, Jozwiak S, Franz DN, Roberts PS, Nieto A, Chung J, et al. Mutational analysis in a cohort of 224 tuberous sclerosis patients indicates increased severity of TSC2, compared with TSC1, disease in multiple organs. Am J Hum Genet. 2001;68:64-80. doi:10.1086/316951.

[21] Rubilar C, López F, Troncoso M, Barrios A, Herrera L. [Clinical and genetic study patients with tuberous sclerosis complex]. Rev Chil Pediatr. 2017;88:41-9. doi:DOI: 10.1016/j.rchipe.2016.08.003.

[22] Staley BA, Vail EA, Thiele EA. Tuberous sclerosis complex: diagnostic challenges, presenting symptoms, and commonly missed signs. Pediatrics. 2011;127:e117-125. doi:10.1542/peds.2010-0192.

[23] Curatolo P, Nabbout R, Lagae L, Aronica E, Ferreira JC, Feucht M, et al. Management of epilepsy associated with tuberous sclerosis complex: Updated clinical recommendations. Eur J Paediatr Neurol EJPN Off J Eur Paediatr Neurol Soc. 2018;22:738-48. doi:10.1016/j. ejpn.2018.05.006.

[24] Webb DW, Clarke A, Fryer A, Osborne JP. The cutaneous features of tuberous sclerosis: a population study. Br J Dermatol. 1996;135:1-5.

[25] Józwiak S, Schwartz RA, Janniger CK, Bielicka-Cymerman J. Usefulness of diagnostic criteria of tuberous sclerosis complex in pediatric patients. J Child Neurol. 2000;15:652-9. doi:10.1177/088307380001501003.

[26] Shepherd CW, Gomez MR, Lie JT, Crowson CS. Causes of death in patients with tuberous sclerosis. Mayo Clin Proc. 1991;66:792-6.

[27] Rakowski SK, Winterkorn EB, Paul E, Steele DJR, Halpern EF, Thiele EA. Renal manifestations of tuberous sclerosis complex: Incidence, prognosis, and predictive factors. Kidney Int. 2006;70:1777-82. doi:10.1038/sj.ki.5001853. 